\title{
A Study on the Efficiency Improvement of Multi-Geothermal Heat Pump Systems in Korea Using Coefficient of Performance
}

\author{
Young-Ju Jung ${ }^{1}$, Hyo-Jun Kim ${ }^{2}$, Bo-Eun Choi ${ }^{2}$, Jae-Hun Jo ${ }^{3}$ and Young-Hum Cho ${ }^{4, *}$ \\ 1 Green Building Center, Korea Productivity Center Quality Assurance, 32 Saemoonan 5th street, Jongno-gu, \\ Seoul 03170, Korea; nun1228@naver.com \\ 2 Department of Architectural Engineering, Graduate School of Yeungnam University, 280 Daehak-Ro, \\ Gyeongsan, Gyeongbuk 38541, Korea; kimyo@ynu.ac.kr (H.-J.K.); vchlqhdmsv@naver.com (B.-E.C.) \\ 3 Department of Architectural Engineering, Inha University, 100 Inha-ro, Nam-gu, Incheon 22212, Korea; \\ jhjo@inha.ac.kr \\ 4 School of Architecture, Yeungnam University, 280 Daehak-Ro, Gyeongsan, Gyeongbuk 38541, Korea; \\ yhcho@ynu.ac.kr \\ * Correspondence: yhcho@ynu.ac.kr; Tel.: +82-53-810-3081; Fax: +82-53-814-3675
}

Academic Editors: Nyuk Hien Wong and Chi-Ming Lai

Received: 8 January 2016; Accepted: 13 April 2016; Published: 12 May 2016

\begin{abstract}
The Korean government is fostering a renewable energy industry as a means of handling the energy crisis. Among the renewable energy systems available, geothermal energy has been highlighted as highly efficient, safely operable and relatively unaffected by outdoors air conditions. Despite the increasing use of renewable energy, the devices using renewables may not be operating appropriately. This study examined current problems in the operation of a geothermal heat pump (GHP) system. The efficiency of a geothermal heat pump system to studied to maximize the operation plan. Our study modelled the target building and analyzed the energy using TRNSYS, which is a dynamic energy simulation tool, to apply the coefficient of performance (COP) and evaluate the operation method. As a result, the GHP total energy consumption from the COP control method was reduced by $46 \%$ compared to the current operation. The proposed control method was evaluated after applying the system to a building. The results showed that efficient operation of a geothermal heat pump system is possible.
\end{abstract}

Keywords: geothermal heat pump (GHP); coefficient of performance (COP); TRNSYS; operation method; renewable energy; building energy; hybrid operation

\section{Introduction}

Indispensable for national economic growth, energy needs to be supplied on a stable basis. The demand for energy is expected to increase in the future with the advances in industrialization, quality of life, etc. On the other hand, the reserves of fossil fuels will reach their limits, which will eventually lead to not only an imbalance between demand and supply and the strategic imperialization of energy, but also to increased environmental contamination and Earth temperature due to the emission of greenhouse gases (GHG) from fuel combustion. The Intergovernmental Panel on Climate Change (IPCC) reported that the total emissions of greenhouse gases should be reduced to $40 \%-70 \%$ by 2050 across the world compared to 2010. According to the report, greenhouse gases increased drastically from 2000 to 2010, caused primarily by increased industrialization, population, life quality improvement, etc. In terms of energy, the emissions are due mainly to the increasing energy consumption in the industrial and building sectors [1]. 
Any problem with the energy supply will give rise to social problems and serious losses to national economies. For example, in South Korea, which has a very high energy consumption, imports cover $95 \%$ of the energy demand [2]. Therefore, specific alternatives and countermeasures must be established to cope systematically with any energy supply problem. In this regard, the South Korean government is focusing its investments on renewable energy and energy efficiency as it sees the expansion of renewable energy supplies as a positive alternative, because renewable energy can both solve the environmental problems and ensure the stability of the energy supply.

In South Korea, there has been a mandate in place since 2004 for public institutions to use renewable energy [3]. Currently, renewable energy must cover $10 \%$ or more of the expected energy consumption in buildings with a total area of $1000 \mathrm{~m}^{2}$ or higher. A geothermal system is highly efficient, environmentally friendly, has a lengthy service life, and has low maintenance costs. Accordingly, geothermal heat pump systems have been addressed by many studies, which have focused on the efficiency enhancement and performance evaluation of underground heat exchangers.

On the other hand, geothermal systems have not been used efficiently after installation at a number of buildings in Korea. Mostly, they are in hybrid operation with existing heating sources, and take the form of a partial load that is responsible for the air conditioning of a building part. In addition, many systems have overcapacity due to the compulsory installation ratios [4]. This results in energy wastage and economic losses. Nevertheless, there are few studies of hybrid operation with existing heating sources. To resolve this problem, this paper proposes an operation method to use geothermal heat pump systems efficiently in combination with existing heat sources.

Several studies have evaluated the performance of geothermal heat pump systems. m published a comprehensive overview of the current international legal status for the use of shallow geothermal energy. In their study, an international survey was performed using a questionnaire sent to more than 60 countries worldwide. Luo et al. [6] and Rees and Curtis [7] examined the importance of the research trends and the design of a GHP system. Nam [8] evaluated system performance through the dynamic energy simulation of heat pump systems using solar heat and geothermal heat, and made a comparative study of the changes in system performance under different climate conditions in two regions. Hwang et al. [9] confirmed the hybrid operation possibility and performance through an experimental performance evaluation. Son et al. [10] predicted the performance of air conditioning and heating through a simulation after assuming the installation of a geothermal heat pump system instead of the existing facilities in a building. Jang [11] performed an experiment to analyze the performance of the system using EES and TRNSYS. In addition, many studies have examined the efficiency of ground heat exchangers, ground circulating water, and temperature. Park [12] measured the change in ground temperature according to depth and analyzed the performance of the heat exchanger and the geothermal heat pump to check the optimal design of a geothermal heat pump system, identify the operating conditions, and determine whether a ground well is suitable for the system. Jung et al. [13] analyzed the coefficient of performance (COP) and consumption energy of a geothermal heat pump unit by the change in flow of ground circulating water. Lee [14] devised an optimal design method by analyzing the design load and consumption data in a geothermal system as the main source with a focus on electricity, air conditioning, and heating energy consumption in the target building. These studies were performed on geothermal heat pump systems from different perspectives, but few studies have examined a hybrid operation method for a geothermal heat pump system with an existing heat source. Bakirci et al. [15] examined the performance of a solar-GSHP system with vertical ground handling equipment (GHE). The results suggested that this solar-GSHP system can be used for heating applications in the cold climate regions of Turkey. Yang [16] assessed the performance characteristics of a vertical U-bend direct-expansion ground source (geothermal) heat pump system (DX GSHPS) for both heating and cooling. Kim et al. [17] reported that the design of a proper indoor temperature for variable outdoor conditions is important for maintaining high system performance and reliability in a hybrid solar-geothermal $\mathrm{CO}_{2}$ heat pump system. Ozgener and Hepbaslib [18] examined the energetic and exergetic modeling of GSHP systems for system analysis and performance assessments. 
Salvalai [19] reported the results of a parameter estimation study of a water-to-water heat pump model, which implemented in the IDA Indoor Climate and Energy (IDA-ICE) simulation environment, and was presented and validated using experimental data.

Ally et al. $[20,21]$ provided excellent data on the energy savings and the fraction of energy that could be extracted from the ground for both space heating and water heating. They reported the advanced building envelope characteristics, instrumentation, data acquisition, tabulated data collected, analysis, measures of performance, and conclusions for ground-coupled heat pumps for reducing the energy footprint in buildings. Chen et al. [22] discussed the use of an underground water-source water-loop heat-pump (UWSWLHP) air-conditioning system for tall apartment buildings in Beijing. Sivasakthivel et al. [23] provided extensive data from India highlighting the energy and $\mathrm{CO}_{2}$ savings potential of the GSHP system. In the case of GSHP, the $\mathrm{CO}_{2}$ emissions were between 4022 million $\mathrm{kg}$ and 12,071 million $\mathrm{kg}$, resulting in approximately a $24.54 \%$ per year reduction. Yoo et al. [24] examined the hybrid operation of an existing heat source and geothermal heat pump system, adding the opening/closing extent of the AHU to the control point and proposing a sequential control by time deferment. On the other hand, studies have focused on the design of geothermal heat pump systems, the performance evaluation of individual systems, and the improvement in efficiency of ground heat exchangers. In South Korea, most buildings used geothermal pumps and existing heat source systems simultaneously, but there is a shortage of studies on how to operate the hybrid heat source. Some relevant studies did not present any specific control method considering the performance of heat pumps. Therefore, the present study developed a sequential operation method of multi-geothermal heat pump systems using the COP to improve their efficiency. Moreover, this study compared the existing operation method with the proposed method through simulation.

The existing heat sources in buildings are chiefly in hybrid use with a geothermal heat pump system, but the problem is that the high-efficiency geothermal heat pump system mainly takes a partial load form, being responsible for the air conditioning of a building part, and is designed separately. Therefore, this study selected a target building with a geothermal heat pump system, analyzed its operation status, checked the problems, and proposed an operation method to improve the efficiency of the multi geothermal heat pump system. This study modelled the target building and analyzed the energy using TRNSYS, a dynamic energy simulation tool, to apply the COP and evaluate the operation method.

\section{Obligatory Renewable Energy Installation System}

In Korea, the Obligatory Renewable Energy Installation System of public buildings is the main applicable legal regime. The Ministry of Trade, Industry and Energy enacted and implemented the "Act on the Promotion of the Development, Use and Diffusion of New and Renewable Energy". Pursuant to its Article 12, Section 2 and Enforcement Decree Article 15, Section 1, a part of the expected annual total energy consumption at any public organization building whose total area for new construction, or extension for reconstruction is $1000 \mathrm{~m}^{2}$ or higher must be supplied with energy produced by renewable energy facilities. Table 1 lists the rates.

Table 1. Renewable energy supply duty rates in Korea.

\begin{tabular}{cccccccccc}
\hline Year & $\mathbf{2 0 1 1 - 2 0 1 2}$ & $\mathbf{2 0 1 3}$ & $\mathbf{2 0 1 4}$ & $\mathbf{2 0 1 5}$ & $\mathbf{2 0 1 6}$ & $\mathbf{2 0 1 7}$ & $\mathbf{2 0 1 8}$ & $\mathbf{2 0 1 9}$ & $\mathbf{2 0 2 0}$ or Later \\
\hline Supply duty rate $(\%)$ & 10 & 11 & 12 & 15 & 18 & 21 & 24 & 27 & 30 \\
\hline
\end{tabular}

The obligatory supply rates of renewable energy can be calculated using Equation (1). The expected energy consumption is calculated by Equation (2), Tables 2 and 3 using the total area of the building and unit energy consumption, purpose-specific correction coefficient, and area coefficient [3]:

$$
\text { Renewable energy supply duty rate }(\%)=\frac{\text { Renewable energy production amount }}{\text { Expected energy consumption amount }} \times 100
$$


Expected energy consumption amount $=$

Total floor area $\times$ Energy consumption rate $\times$ Correction factor $\times$ Area coefficient

Table 2. Building purpose-specific unit energy consumption and correction coefficients.

\begin{tabular}{cccc}
\hline & Category & $\begin{array}{c}\text { Unit Energy Consumption } \\
\left.\mathbf{( k W h} / \mathbf{m}^{\mathbf{2}} \cdot \mathbf{\text { year }}\right)\end{array}$ & $\begin{array}{c}\text { Purpose-Specific } \\
\text { Correction Coefficient }\end{array}$ \\
\hline \multirow{3}{*}{ Public purpose } & Correctional and military facilities & 392.07 & 1.64 \\
& Broadcasting and communication facilities & 490.18 & 1.31 \\
& Business facilities & 371.66 & 1.73 \\
\hline & Culture and assembly facilities & 412.03 & 1.56 \\
& Religious facilities & 257.49 & 2.50 \\
Educational and & Medical facilities & 643.52 & 1.00 \\
social facilities & Education and research facilities & 231.33 & 2.78 \\
& Facilities for the elderly and infirm & 175.58 & 3.67 \\
& Training facilities & 231.33 & 2.78 \\
& Sports facilities & 235.42 & 2.73 \\
& Cemetery-related facilities & 234.99 & 2.74 \\
& Sightseeing and rest facilities & 437.08 & 1.47 \\
Commercial purpose & Funeral hall & 234.99 & 2.74 \\
& Sales and operation facilities & 408.45 & 1.58 \\
& Transport facilities & 374.47 & 1.72 \\
& Business facilities & 374.47 & 1.72 \\
& Lodging facilities & 526.55 & 1.22 \\
\hline
\end{tabular}

Table 3. Regional coefficients according to climate conditions in Korea.

\begin{tabular}{cccccccc}
\hline Category & Seoul & Incheon & Daegu & Busan & Gwangju & Daejeon & Jeju \\
\hline Regional coefficient & 1.00 & 0.97 & 1.04 & 0.93 & 1.01 & 1.00 & 0.97 \\
\hline
\end{tabular}

Similarly, renewable energy was distributed and expanded, but the systems are often operated without knowing even the efficiency or load distribution ratio. In addition, renewable facilities are often responsible for partial loads and designed for overcapacity to meet legal standards. Therefore, it is necessary to improve the energy efficiency using renewable energy resources preferentially.

\section{Multi-Geothermal Heat Pump System Operation Method Using COP}

Geothermal heat pumps are installed according to the mandated renewable energy installation system, but the focus is often placed on the obligatory capacity alone rather than the efficient use of the system. Although efficient and environmentally friendly, heat pump systems are often responsible for the partial load of a building. The independent use of a geothermal heat pump system often focuses on the mere adjustment to meet the legal capacity obligations rather than the building load, which leads to overdesign compared to a shared load. This paper proposes an operation method to save energy by upgrading the device efficiency using COP, using the remaining energy of a geothermal heat pump system preferentially, and reducing the use of the existing heat source in a selected building.

\subsection{Analysis of Existing Multi-Geothermal Heat Pump System}

The target is a university hospital building located in Gyeongsangbuk-do. The building has a total area of approximately $81,928 \mathrm{~m}^{2}$ and consists of three stories below ground and nine stories above ground. The system operates a $530 \mathrm{RT}$ geothermal heat pump according to the obligatory renewable energy installation system. Table 4 provides an overview of the target building.

The building has twelve 530 RT geothermal heat pumps, and three $800 \mathrm{RT}$ and one $500 \mathrm{RT}$ absorption chiller-heaters. As shown in Figure 1, the building has separate spaces for the geothermal heat pump and absorption chiller-heater, and the heat source water produced is supplied to the air handling unit (AHU) applicable zones. The absorption chiller-heater is responsible for the entire 
geriatric ward and the higher part of the main building, while the geothermal heat system air-conditions the lower part of the main building and the cancer center. A total of 32 AHUs are present, of which seven and 25 AHUs correspond to the geothermal heat pump and the absorption chiller-heater, respectively. The operating amount control is a variable control method for the amount of equipment according to the indoor load and is established by both the geothermal heat pump and the absorption chiller-heater based on the cold and hot water supply temperatures.

Table 4. Summary of the building information.

\begin{tabular}{cc}
\hline List & Contents \\
\hline Building name & K University Hospital \\
Building purpose & Medical and funeral services \\
Number of floors & Three stories below, nine above the ground \\
Building area & $9737 \mathrm{~m}^{2}$ \\
Total area & $81,929 \mathrm{~m}^{2}$ \\
Hospital purpose & Main building-three stories below, nine above the ground \\
& Geriatric ward-One story below, seven above the ground \\
Cancer ward-two stories below, five above the ground & $2263 \mathrm{~m}^{2}$ \\
Geothermal heat pump capacity & $530 \mathrm{RT}^{1}$ \\
\hline
\end{tabular}

${ }^{1}$ RT: Refrigeration Ton.

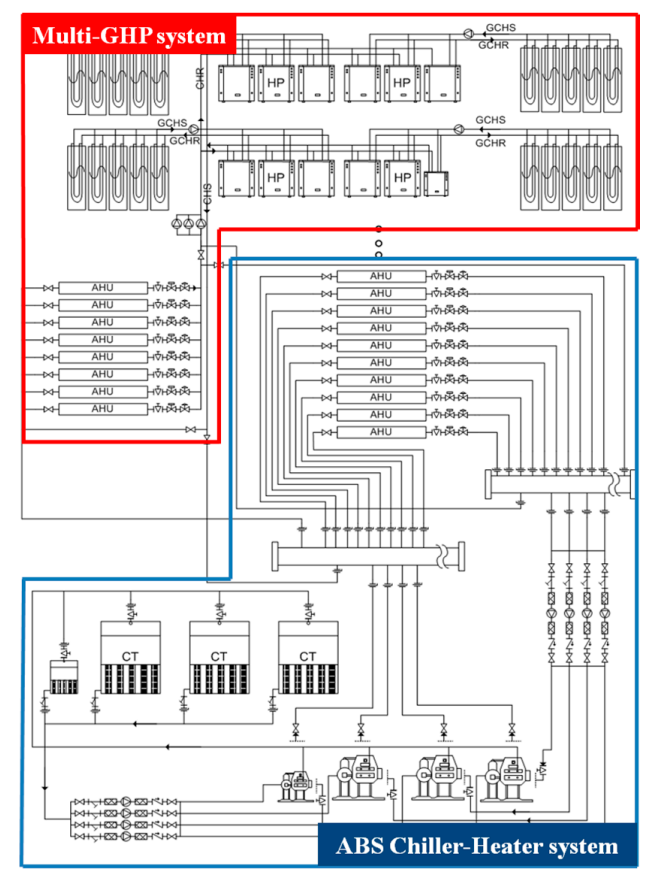

Figure 1. System diagram of the hybrid operation method for the geothermal heat pump system and absorption chiller-heater.

The geothermal heat pump system is not used efficiently due to system separation from the absorption chiller-heater. A problem is encountered due to the operating amount control of the geothermal heat pump system by the cold and hot water supply temperatures; every geothermal system is operated continually to meet the set temperature, even in the case of a low load.

\subsection{Existing Multi-Geothermal Heat Pump System}

This study used TRNSYS 17, a dynamic energy simulation tool, to evaluate the performance of the multi-geothermal heat pump system installed at the target building. As shown in Figure 2, the target 
building was modelled using the TRNSYS 3D of Google Sketch up, the detailed data was entered and the HVAC system established using Trnbuild modeling and Simulation Studio modeling. Tables 5 and 6 list the equipment data and the indoor room conditions, respectively.

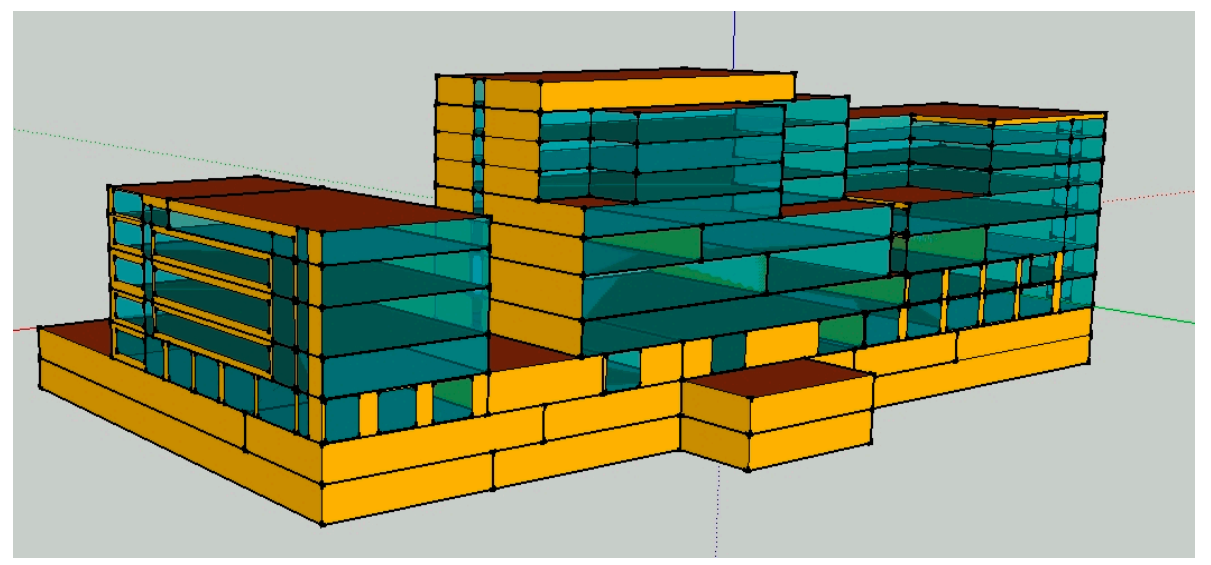

Figure 2. Target building TRNSYS 3D modeling.

Table 5. Geothermal heat pump and absorption chiller and heater data information.

\begin{tabular}{cccc}
\hline \multicolumn{1}{c}{ Lists } & & Geothermal Heat Pump & Absorption Chillers and Heater \\
\hline \multirow{2}{*}{ Capacity } & Cooling & $46.24 \mathrm{RT}$ & $800 \mathrm{USRT}$ \\
& Heating & $48.86 \mathrm{RT}$ & $2,419,500 \mathrm{Kcal} / \mathrm{h}$ \\
\hline \multirow{2}{*}{ Leaving temperature } & Cooling & $7{ }^{\circ} \mathrm{C}$ & $7{ }^{\circ} \mathrm{C}$ \\
& Heating & $45^{\circ} \mathrm{C}$ & $60^{\circ} \mathrm{C}$ \\
\hline \multirow{2}{*}{ Entering temperature } & Cooling & $12^{\circ} \mathrm{C}$ & $12^{\circ} \mathrm{C}$ \\
& Heating & $40^{\circ} \mathrm{C}$ & $55^{\circ} \mathrm{C}$ \\
\hline
\end{tabular}

Table 6. Individual room set points.

\begin{tabular}{ccccc}
\hline \multirow{2}{*}{ Room } & \multicolumn{2}{c}{ Temperature $\left({ }^{\circ} \mathbf{C}\right)$} & \multicolumn{2}{c}{ Humidity (\%) } \\
\cline { 2 - 5 } & Summer & Winter & Summer & Winter \\
\hline Ward & 26 & 23 & 55 & 45 \\
Department of pharmacy & 26 & 22 & 55 & 45 \\
Outpatient department & 26 & 22 & 55 & 45 \\
Operating room & 24 & 24 & 50 & 50 \\
Recovery room & 24 & 25 & 55 & 50 \\
Office & 26 & 20 & 55 & 45 \\
Assembly hall & 26 & 20 & 55 & 45 \\
\hline
\end{tabular}

\subsubsection{Control Methods for the Existing Geothermal Heat Pump}

A control was established based on the operating amount control by the set temperature of the existing geothermal heat pump system through the system composition of a geothermal heat pump, temperature sensor and AHU. The strategy followed was to operate the system if a set indoor temperature reaches its upper limit $($ Tset $+d)$ with a temperature sensor attached to the cold and water pipe of the geothermal heat pump system. The operating amount control was established according to whether the set temperature is met or not. Make on/off control is set up to stop operation if the set temperature reaches its lower limit (Tset $-\mathrm{d})$. Figure 3 presents the control algorithm. 


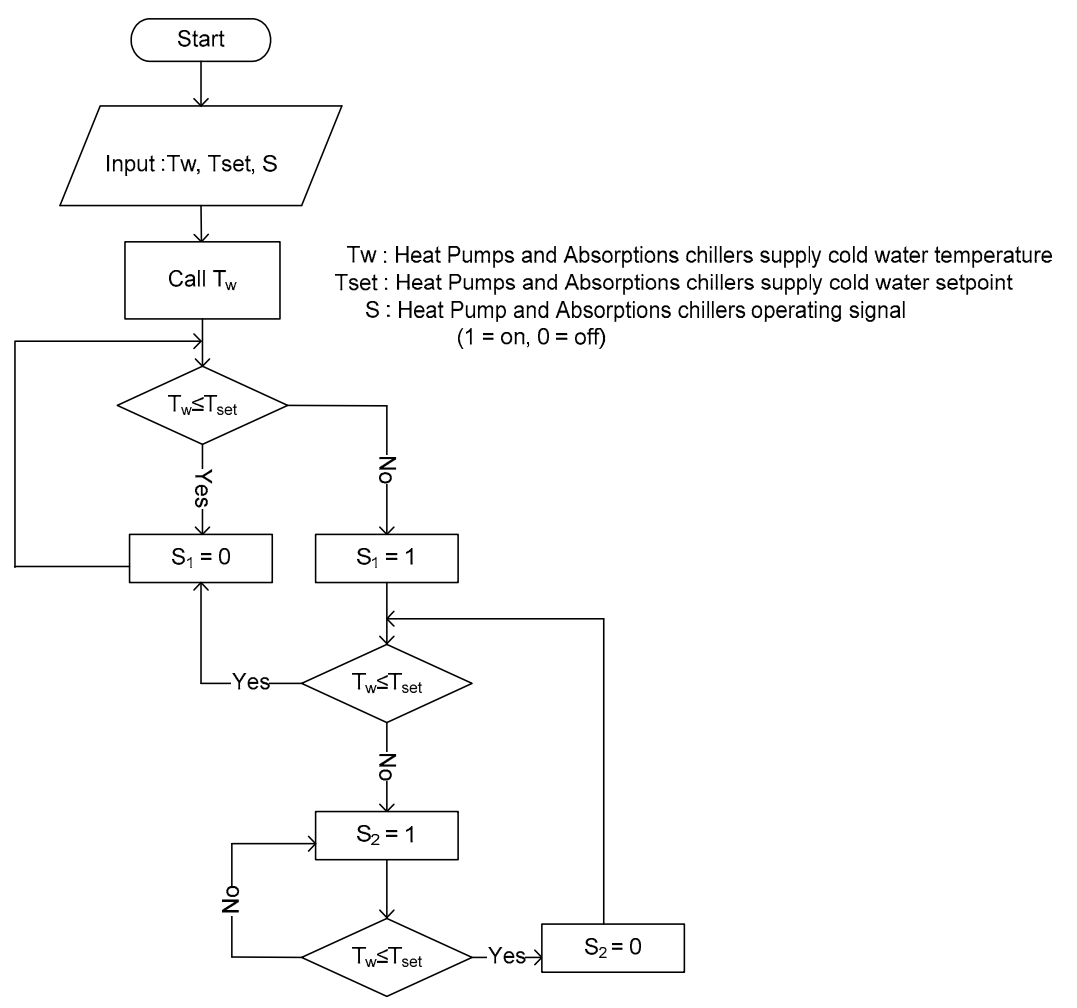

Figure 3. Control methods for an existing GHP.

(1) If no heat pump system is currently operated:

Operate a heat pump, if its leaving water temperature is higher than its set temperature. Subsequently, determine the operation of a next heat pump according to whether to control the set temperature. Maintain a current status, unless the leaving water temperature is higher than the set temperature.

(2) If a heat pump system is currently operated:

Stop the operation of the heat pump, if its leaving water temperature is higher than its set temperature. If the heat pump leaving cold water temperature is higher than its setpoint, operate a next heat pump additionally to adjust the setpoint. Stop the operation of the heat pump system sequentially, if the leaving water temperature is lower than the setpoint.

\subsubsection{Performance Evaluation of Existing Geothermal Heat Pump}

The coefficient of performance (COP) is used as a criterion to judge the heat efficiency of a heat source system. As shown in Figure 4, the maximum COP was 4.2 and the energy consumption was lowest at the maximum COP according to the simulation result of the geothermal heat pump system in the target building.

Figure 5a shows the summer cold water entering and leaving temperatures and COPs of the existing geothermal heat pump system. The cold water leaving and entering temperatures were on average $7.51{ }^{\circ} \mathrm{C}$ and $7.91{ }^{\circ} \mathrm{C}$, respectively, and the COPs were a maximum of 4.1 with an average of 3.55.

Figure $5 \mathrm{~b}$ shows the winter hot water entering and leaving temperatures and the COPs of the existing geothermal heat pump system. The hot water leaving and entering temperatures were on average $43.46^{\circ} \mathrm{C}$ and $41.71{ }^{\circ} \mathrm{C}$, respectively, and the COPs were a maximum of 4.2 and an average of 3.59. The COP did not reach the maximum value of 4.2 and remained around 3.5 on average throughout the year on account of the operating amount control of the geothermal heat pump system for the set temperature control of the cold and hot water supplied to the load side. 


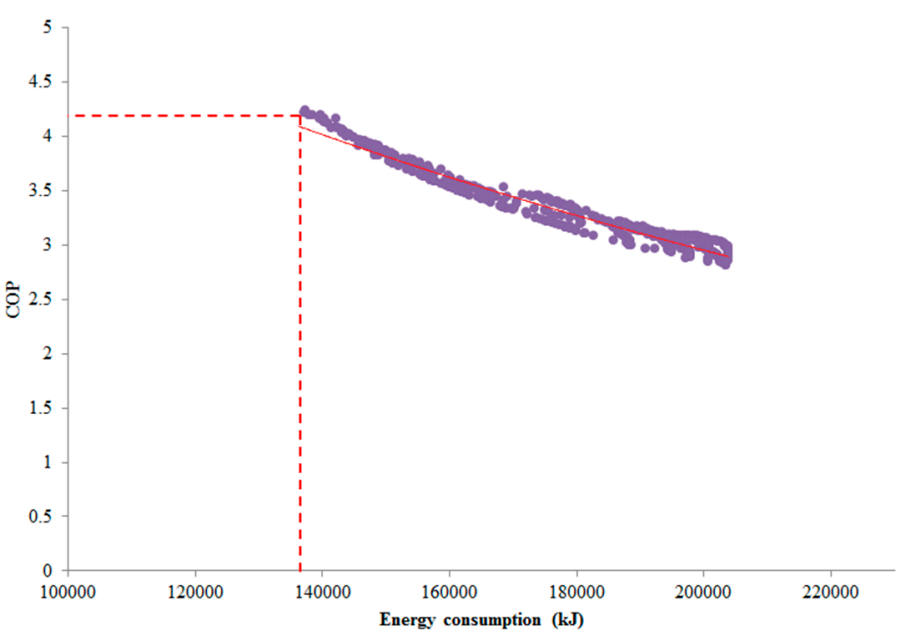

Figure 4. COP and energy consumption relationship in the GHP system.

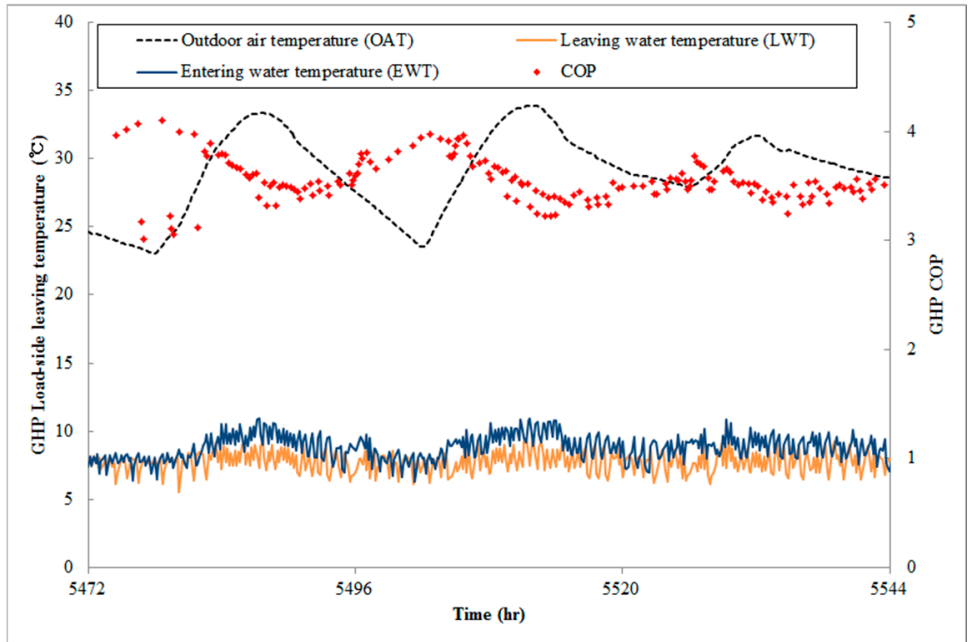

(a)

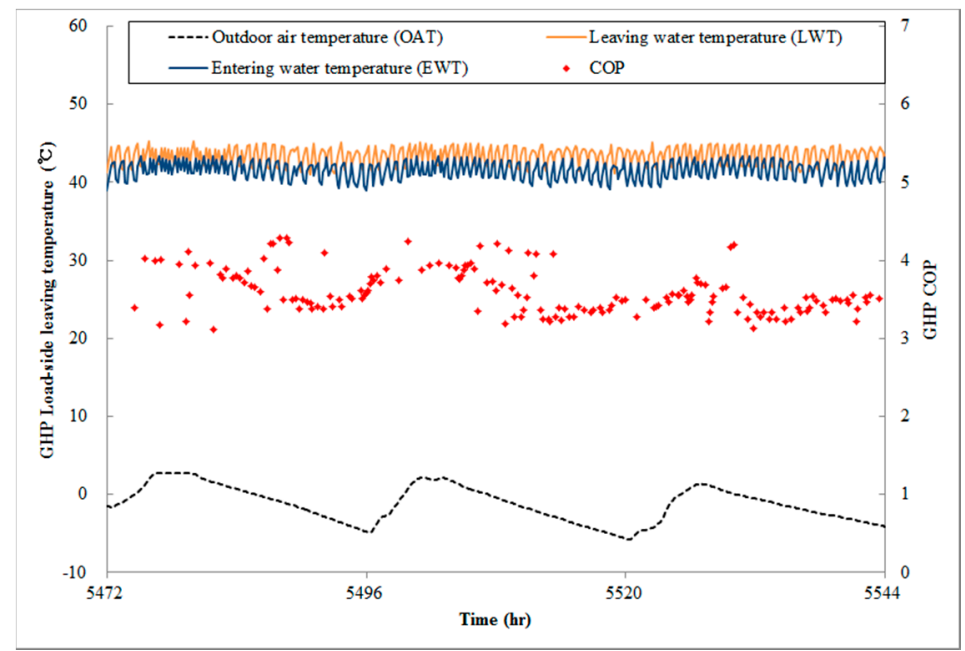

(b)

Figure 5. Entering and leaving temperatures and COPs of the existing geothermal heat pump system: (a) Summer; (b) Winter. 
The operating amount control by the set temperature is simple and reflects the room load indirectly. On the other hand, even when there is no load in the conditioning space, the system is operated to meet the set temperature of the leaving water temperature, leading to unnecessary energy consumption. Geothermal heat pumps are operated individually, leading to a waste of energy and the lowering of the COP. This problem makes it necessary to establish ways of reducing energy wastage without limiting the set point of the leaving water temperature. Therefore, an energy-efficient system control can be established if the geothermal heat pump system is controlled based on the maximum COP.

\subsection{Multi Geothermal Heat Pump System Control Method Using Coefficient of Performance (COP)}

\subsubsection{COP Monitoring Method}

This study evaluated a method to effectively apply low-cost and high-level COP monitoring to a building control and diagnosis system to effectively control the geothermal heat pump system. A calculation process was extracted using Equations (3)-(5) to obtain the necessary factors in the case of the COP calculation.

(1) Step 1. Determine Power Consumption Model

$$
\begin{gathered}
\eta_{v}=\frac{\dot{V}_{s u c}}{\dot{V}_{D}}=\frac{\dot{N} V_{s u c}}{\dot{N} V_{D}}=\frac{V_{s u c}}{V_{D}}=1-\frac{c}{1-c}\left[\left(\frac{P_{d i s}}{P_{s u c}}\right)^{1 / m}-1\right] \\
\dot{m}=\frac{\dot{V}_{s u c}}{v_{s u c}}=\frac{\eta_{v} \dot{V}_{D}}{V_{s u c}}=\frac{\eta_{v} \dot{N} V_{D}}{v_{s u c}} \\
\dot{W}=\dot{m} w=\dot{m}\left\{p_{s u c} v_{s u c} \frac{m}{m-1}\left[\left(\frac{P_{\text {dis }}}{P_{\text {suc }}}\right)^{(m-1) / m}-1\right]\right\}
\end{gathered}
$$

where, $\eta_{v}=$ volumetric efficiency; $\dot{V}_{D}=$ compressor displacement rate; $\dot{N}=$ the number of suction strokes per unit time (rpm); $V_{D}=$ the volume of the suction chamber(s) $\left(\mathrm{m}^{3}\right) ; \dot{V}_{\text {suc }}=$ actual volumetric flow rate evaluated at the suction condition; $\mathrm{m}=$ empirical parameter; $P_{s u c}=$ pressure at the suction condition; $\dot{W}=$ power consumption; $\dot{m}=$ mass rate of refrigerant flow; $v_{s u c}=$ specific volume at suction condition; $w=$ specific work; $c=$ clearance factor.

(2) Step 2. The performance of a geothermal heat pump is generally represented by COP and can be calculated using Equation (6):

$$
\mathrm{COP}=\frac{Q}{\dot{W}}
$$

where, $\mathrm{Q}=$ capacity $(\mathrm{kW}) ; \dot{W}=$ power consumption $(\mathrm{kW})$.

\subsubsection{Sequential Control Methods by Coefficient of Performance in a Multi-Geothermal Heat Pump}

The control of a geothermal heat pump system is made possible by the highest-efficiency and lowest energy. High efficiency can be produced with the lowest energy, if sequential control is applied to the geothermal heat pump system based on the optimal COP. In Figure 4, the maximum COP was 4.2 in the geothermal heat pump system of the target building. This study evaluated a method to control the geothermal heat pump system sequentially to maintain the maximum COP. Figure 6 shows a sequential control method algorithm of the geothermal heat pump by COP. 


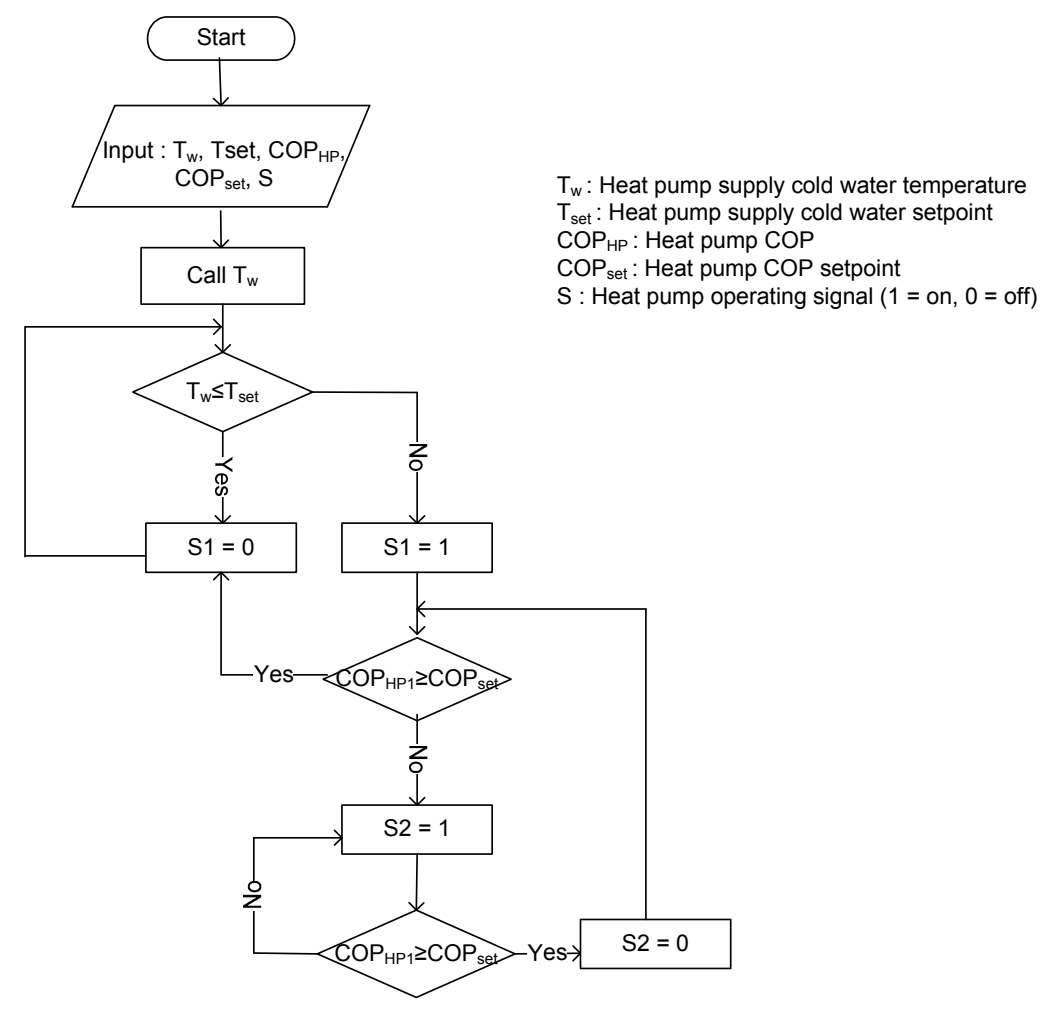

Figure 6. Sequential control method algorithm by the COP.

(1) If no heat pump system is currently operated:

Operate a heat pump if its leaving water temperature is higher than its set temperature $(\mathrm{Tw}>\mathrm{Tse}+\mathrm{d})$. Operate the following heat pump if the COP of the first heat pump does not bear the load of a room, even when it reaches the $\mathrm{COP}_{\mathrm{SET}}$. Maintain the current status, unless the leaving water temperature is higher than the set temperature.

(2) If a heat pump system is currently operated:

Stop the operation of the first heat pump if its leaving water temperature is higher than its set temperature $(\mathrm{Tw}<\mathrm{Tset}+\mathrm{d})$. Operate the following heat pump because the load of a room is not borne if the COP of the first heat pump is higher than its set value $\left(\mathrm{COP}_{\mathrm{HP}}>\mathrm{COP}_{\text {set }}+\mathrm{d}\right)$.

Figure 7 shows a comparison of energy consumption between existing and sequential control methods at a geothermal heat pump. HP 4 satisfied most loads when the sequential operation method by COP was applied to a multi-geothermal heat pump system. Even when the load of a building is met by the mere high-efficiency geothermal heat pump, both heat-source systems are operated and thus energy is wasted. It was possible to use a geothermal heat pump system better, since there was less air conditioning load than the design capacity of the geothermal heat pump system. Therefore, it will be possible to improve energy efficiency, if the remaining energy of the geothermal heat pump system is used to lower the load distribution ratio if the existing absorption chiller-heater and maximize the use of the geothermal heat pump system. 


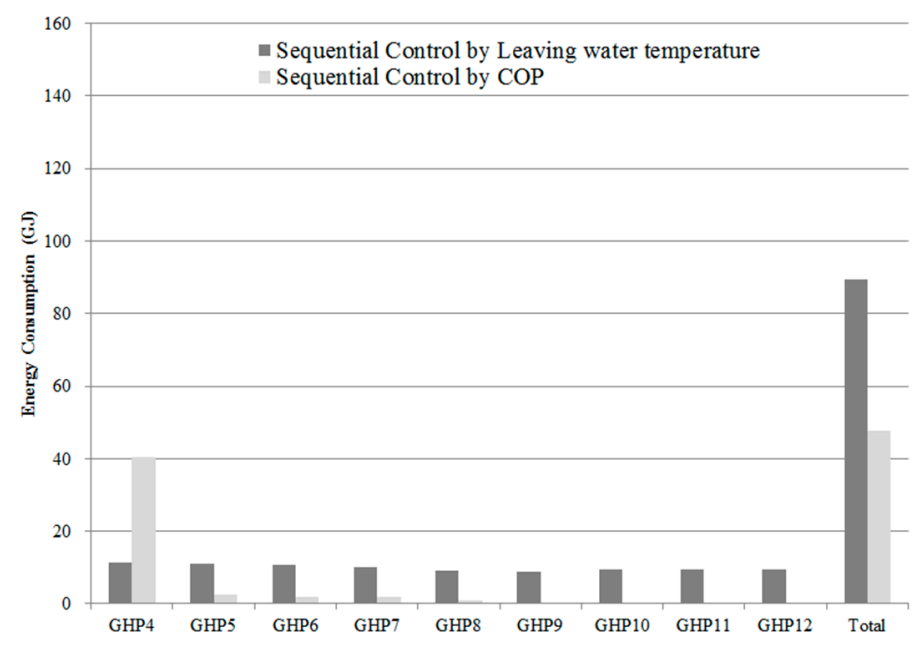

Figure 7. Comparison of the energy consumption at GHPs.

\subsection{Hybrid Operation Method for a Geothermal Heat Pump System and Existing Heat Source}

This paper proposes a hybrid operation method by integrating the distribution with the absorption chiller-heater and the multi-geothermal heat pump system such as Figure 8. The hybrid operation method involves supplying the heat source amount for each heat source system to a header and distributing it to each AHU. If the load is small due to the connection of the heat source system, the geothermal heat pump system can be considered to make air conditioning possible. Therefore, it will be necessary to set the set temperatures of the two heat source systems equally. This will be an operation method for improving the energy efficiency to use the remaining energy of the geothermal heat pump system preferentially, reduce the use of the existing heat source, as well as maximize the operation of the geothermal heat pump system and minimize the use of the existing heat source, i.e., the absorption chiller-heater. Figure 9 shows the hybrid operation method in an algorithm.

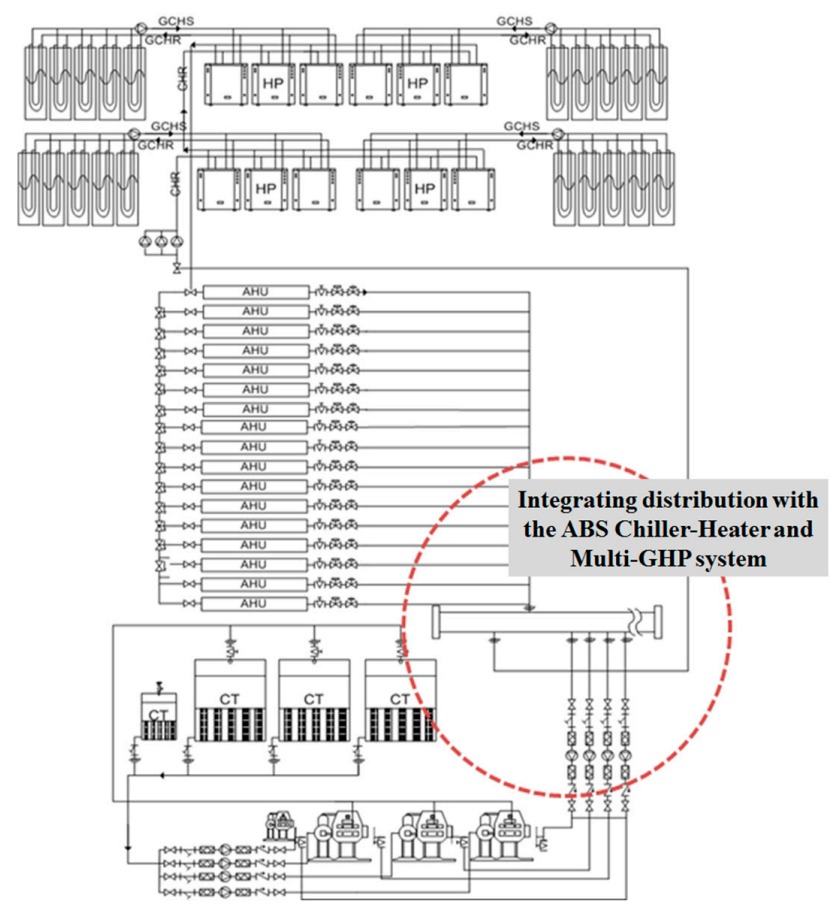

Figure 8. System diagram on the hybrid operation method for GHP system and absorption chiller-heater. 


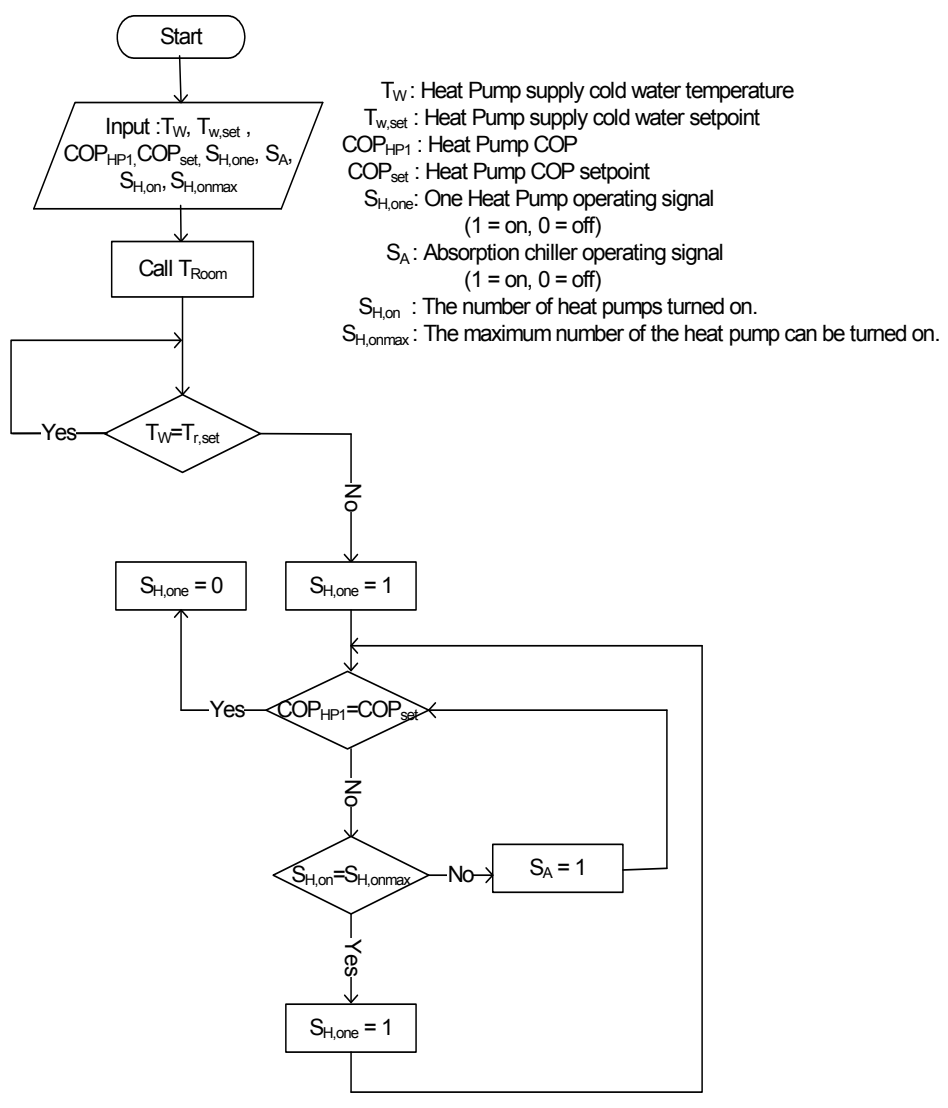

Figure 9. Hybrid operation method for GHP system and absorption chiller-heater.

(1) If no heat pump system is currently operated:

Operate a heat pump if its leaving water temperature is higher than its set temperature $(\mathrm{Tw}>\mathrm{Tse}+\mathrm{d})$. Operate the following heat pump if the COP of the first heat pump does not bear the load of a room, even when it reaches the COPSET. Maintain the current status unless the leaving water temperature is higher than the set temperature.

(2) If a heat pump system is currently operated:

Stop the operation of the first heat pump if its leaving water temperature is higher than its set temperature $(\mathrm{Tw}<\mathrm{Tset}+\mathrm{d})$. Operate the following heat pump because the load of a room is not borne if the COP of the first heat pump is higher than its set value (COPHP $>$ COPset $+d$ ). Begin the operation of the absorption chiller-heater if no load is borne, even when the geothermal heat pump system is operated at the maximum.

\section{Evaluation of Geothermal Heat Pump System Operation Method Using COP}

According to the existing operation method, the multi-geothermal heat pump system was subjected to operating amount control based on the cold and hot water supply temperatures, and was operated in system separation from the existing heat source, i.e., the absorption chiller-heater. Therefore, this study applied a sequential control using the COP to improve the efficiency of the multi-geothermal heat pump system, and proposed a hybrid operation method with an integral system to use the geothermal heat pump system with more efficiency than the existing heat source. Table 7 provides a summary of the simulation CASE. 
Table 7. Simulation CASE.

\begin{tabular}{cc}
\hline Existing CASE & Proposed CASE \\
\hline Sequential Control by Coefficient of Performance in & Sequential Control by Coefficient of Performance in \\
Multi Geothermal Heat Pump System & Multi Geothermal Heat Pump System \\
+ & + \\
Separation Operation Method for Geothermal Heat & Hybrid Operation Method for Geothermal Heat \\
Pump System and Absorption Chiller-Heater & Pump System and Absorption Chiller-Heater \\
\hline
\end{tabular}

\subsection{Analysis of Temperatures and COP at GHP System}

Figure 10a shows the results obtained by applying the sequential operation method by the summer $\mathrm{COP}$ to the geothermal heat pump system. The leaving and entering temperatures were on average $12.33^{\circ} \mathrm{C}$ and $13.33^{\circ} \mathrm{C}$, respectively. The COPs were on average 4.1 with a maximum of 4.2.

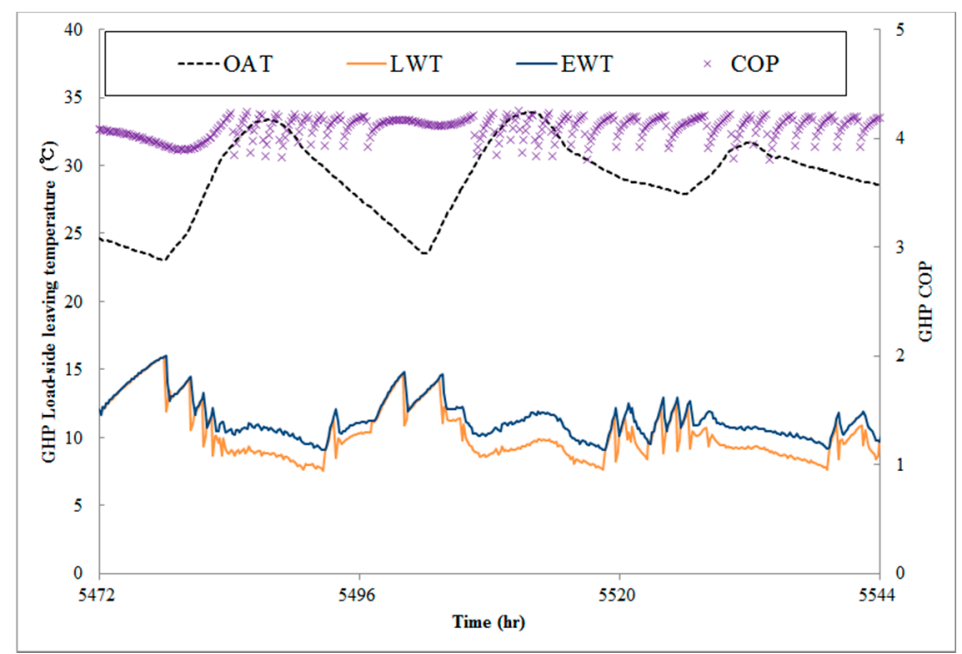

(a)

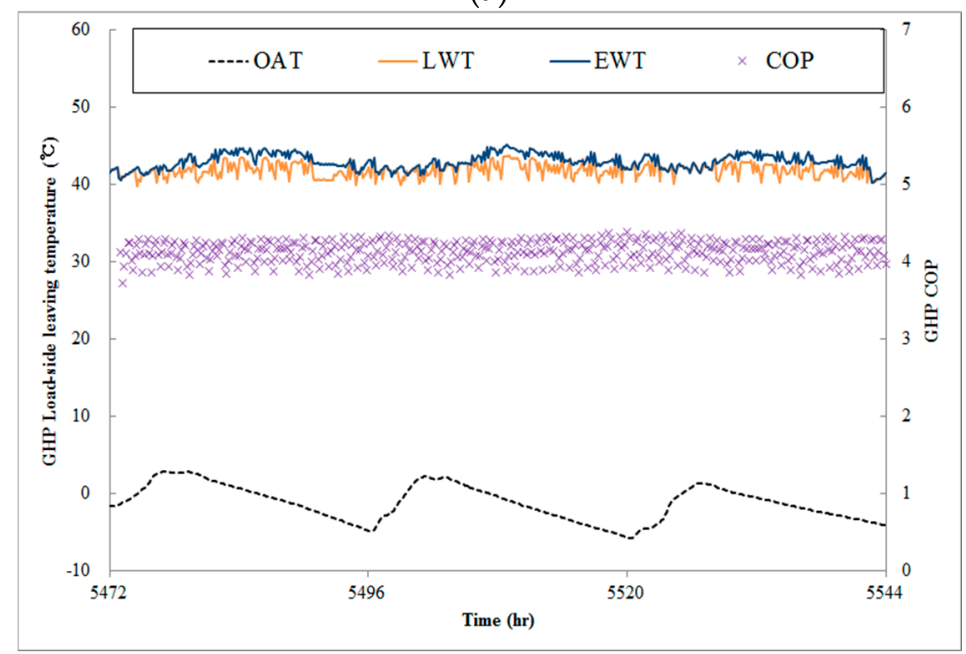

(b)

Figure 10. Entering and leaving temperatures and COPs of GHP system by COP sequential control: (a) Summer; (b) Winter.

Figure 10b presents the results obtained by applying the sequential operation method by the winter COP to the geothermal heat pump system. The leaving and entering temperatures were on average $42.3^{\circ} \mathrm{C}$ and $41.5^{\circ} \mathrm{C}$, respectively. The COPs were on average 4.12 with a maximum of 4.2. 
In both summer and winter, the COP was improved with sequential control in the multi-geothermal heat pump system.

\subsection{Analysis of the Indoor Environment}

Figures 11 and 12 present graphs showing the representative indoor temperature in summer and winter with the indoor temperature set to $24^{\circ} \mathrm{C}$. In hospitals, it is more important to keep the building occupants comfortable than in other types of buildings, and it is necessary to control the indoor temperature properly.

According to the simulation, it was possible to control the indoor temperature within the set difference with both methods. The nearer the method drew to the sequential operation method, the more the difference in the average indoor temperature was reduced. This shows that it is possible to control the indoor temperature comfortably and stably in an indoor heated environment.

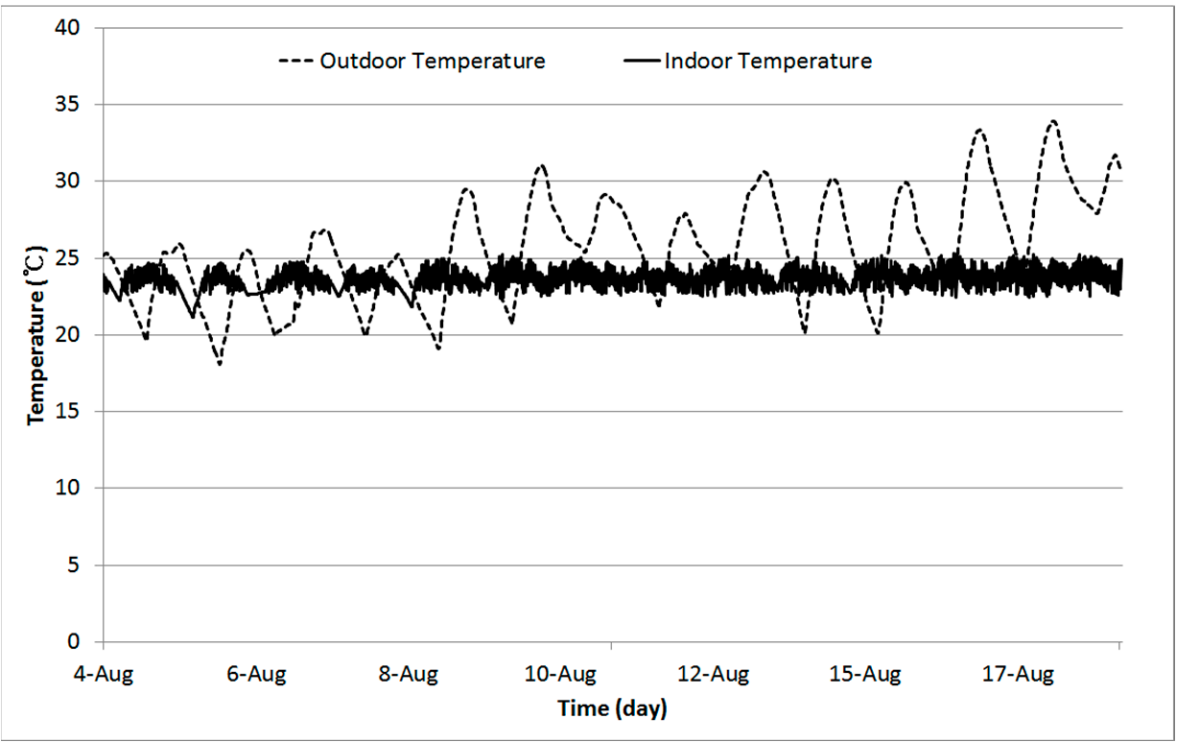

(a)

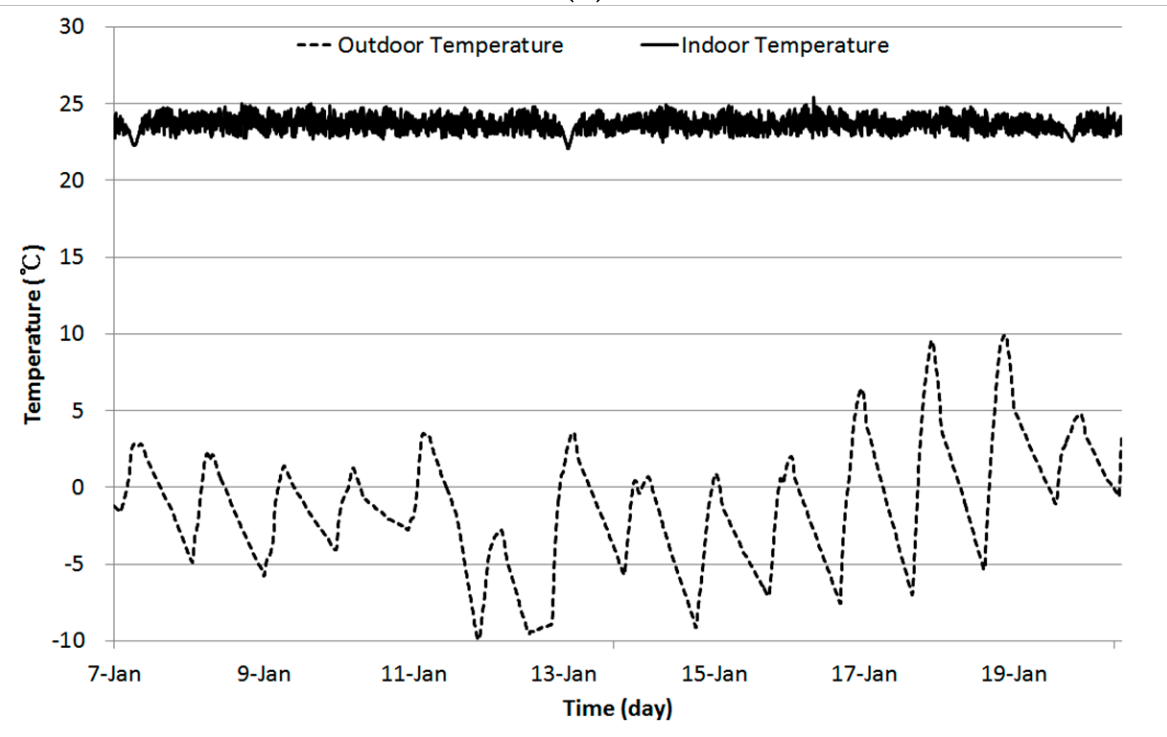

(b)

Figure 11. Indoor temperature in the existing CASE: (a) Summer; (b) Winter. 


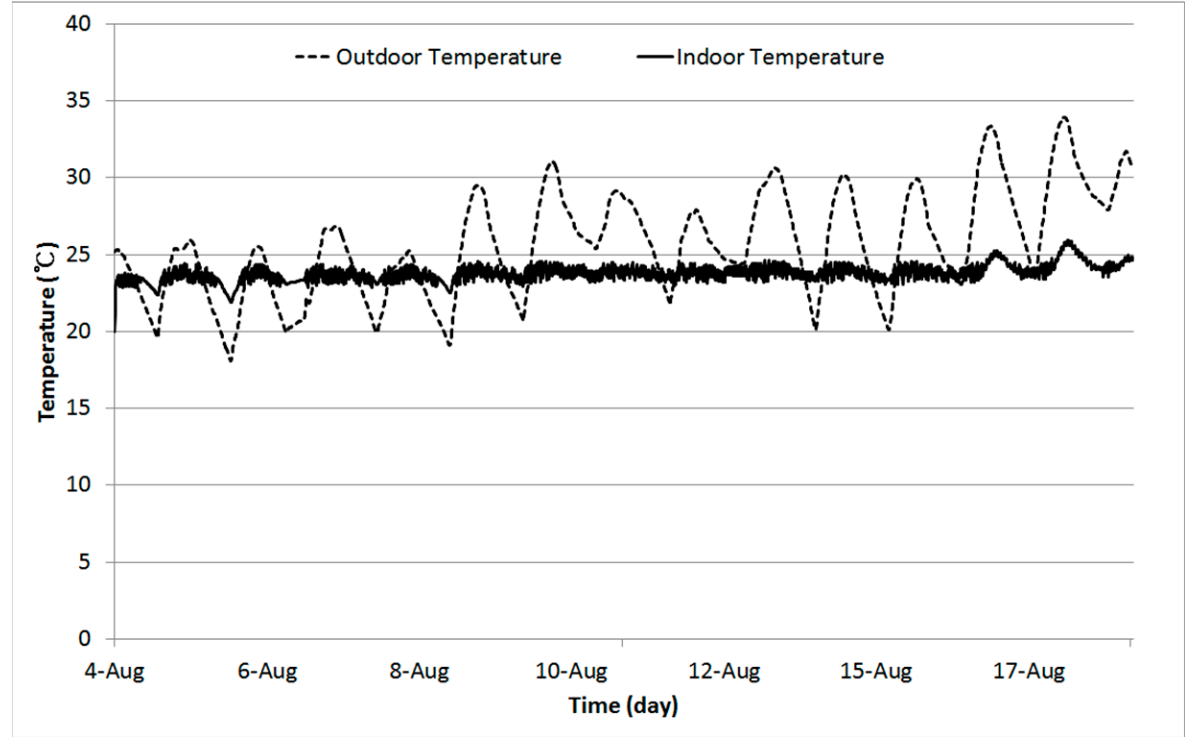

(a)

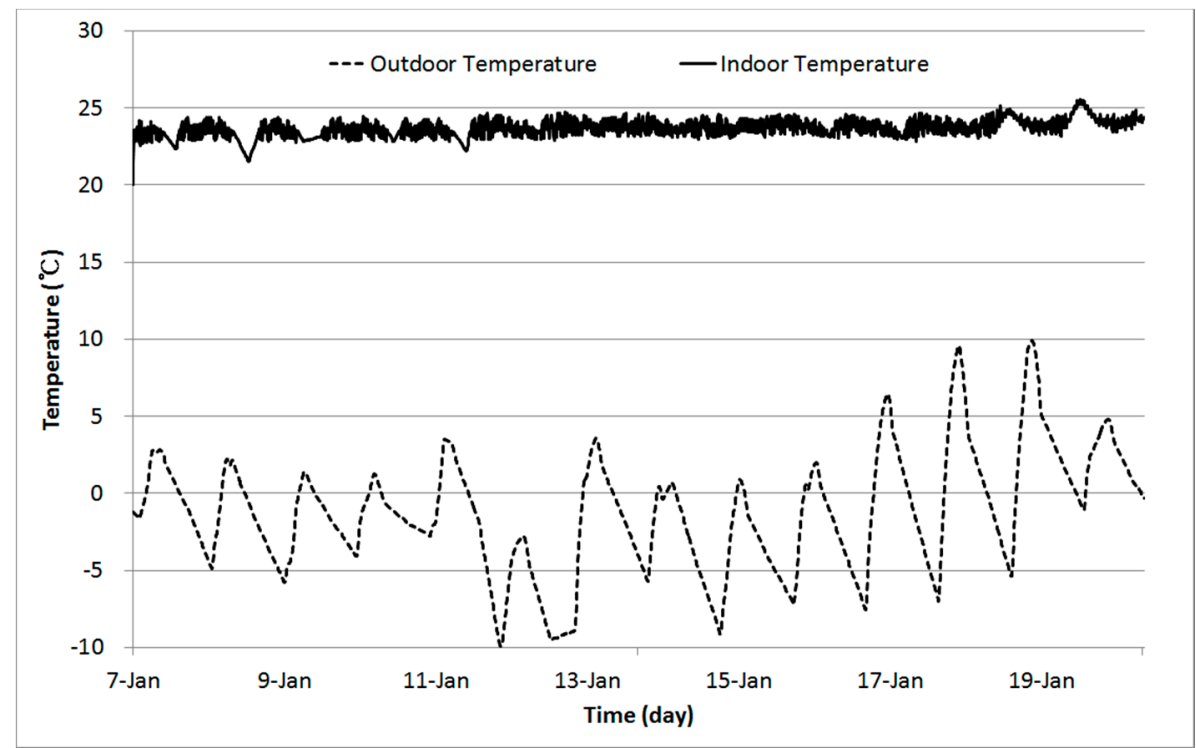

(b)

Figure 12. Indoor temperature in the proposed CASE: (a) Summer; (b) Winter.

\subsection{Analysis of Energy Consumption}

Figure 13 presents a graph comparing the energy consumption of the geothermal heat pump systems using the existing and proposed operation methods. Each heat pump showed an increase in energy consumption according to the sequential operation method by the COP and the proposed operation method, which preferentially uses a high-efficiency geothermal heat pump system in the system integration with an absorption chiller-heater.

Figure 14 shows the total energy consumption of the geothermal heat pump system and the absorption chiller-heater. In terms of energy consumption, compared to the existing operation method, which uses the geothermal heat pump system and the absorption chiller-heater in system separation, the geothermal heat pump system showed an approximately $35 \%$ increase, while the absorption chiller-heater showed an approximately $45 \%$ decrease, according to the hybrid operation method of the geothermal heat pump system and the absorption chiller-heater. As a result, the total energy consumption decreased by approximately $40 \%$. The sequential operation by the COP made it possible 
to operate the geothermal heat pump system efficiently, and the hybrid operation with the absorption chiller-heater made it possible to bear the load, to apply the remaining energy of the geothermal heat pump system to the load of the existing absorption chiller-heater, and lower the share ratio of load, as well as reduce the energy consumption of the existing heat source by maximizing the use of the geothermal heat pump system.

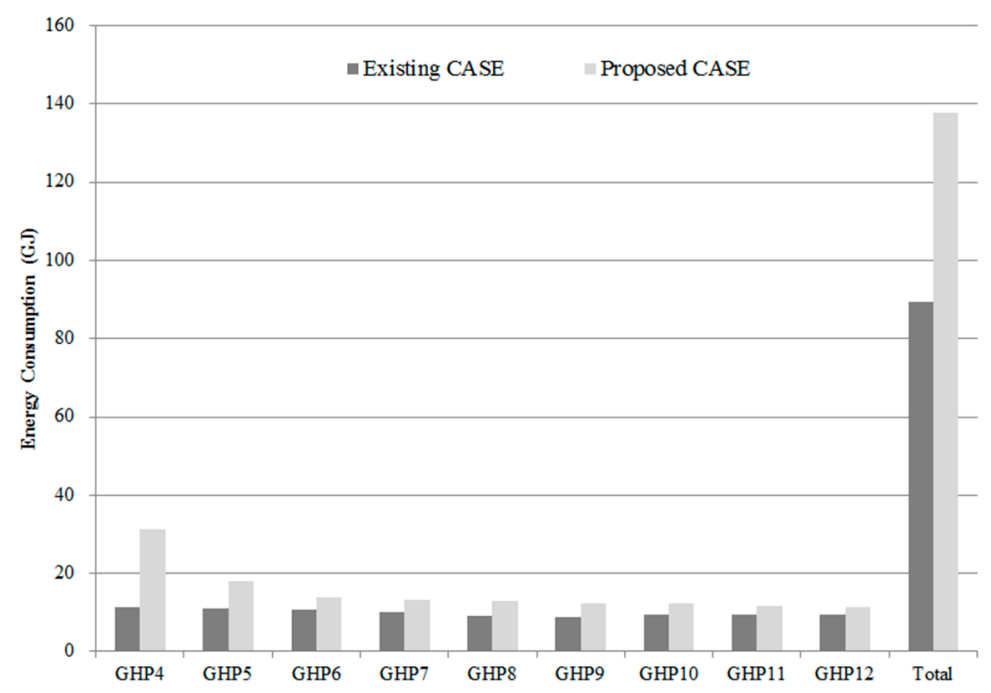

Figure 13. Energy consumption of each GHP in hybrid GHP Operation Method.

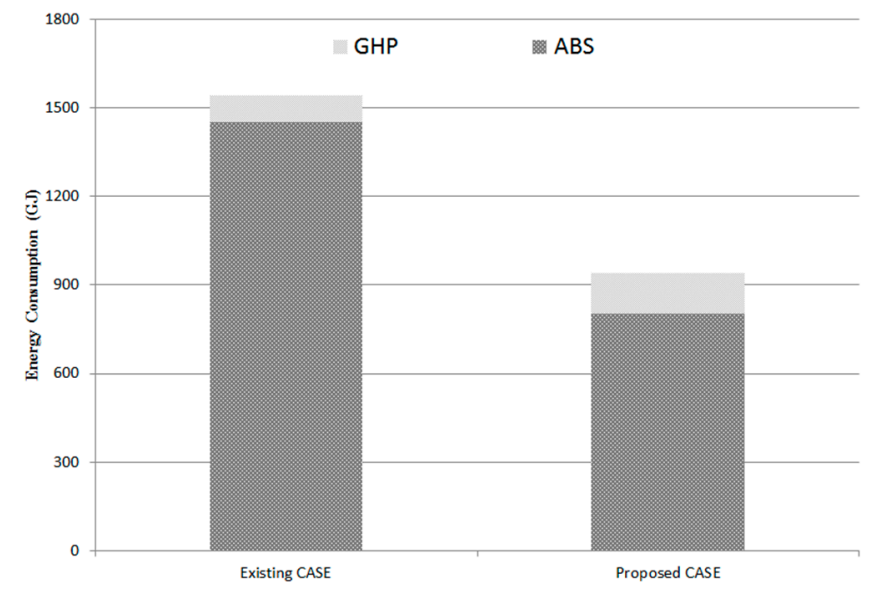

Figure 14. Energy consumption of the absorption chiller-heater and GHP System.

\subsection{Relationship between COP and Load at Geothermal Heat Pump System}

Figure 15 presents the results of the analysis of the COP relationship according to the load. Under the same load condition, a heat pump showed a higher performance in the case of the application of sequential control by COP. The existing operation method shows that the heat pump has a low efficiency because the on/off control is used according to the cold water temperature irrespective of the efficiency of the heat pump. On the other hand, sequential control by the COP showed high efficiency because the control is perfomed in a good efficiency state with the optimal COP. 


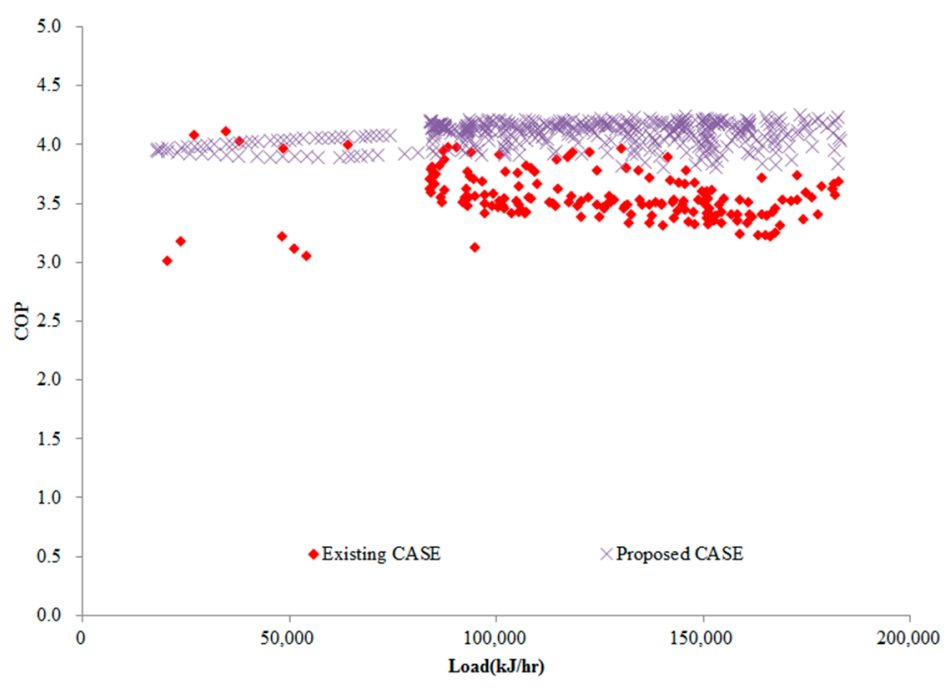

Figure 15. COP and load relationship in the GHP system.

\section{Conclusions}

A geothermal heat pump system was installed to meet the legal standards under the renewable energy installation duty system, but it is not used efficiently due to over-design and a designed separation from the existing heat source. Therefore, the present study proposed a sequential operation method by COP to maximize the efficiency of the geothermal heat pump system. Subsequently, this study proposed an operation method to maximize and minimize the use of a high-efficiency geothermal heat pump system and the existing heat source, respectively, and evaluated it through a simulation:

(1) The geothermal heat pump of the target building was operated to adjust the supply temperature on the side of load to the set point, and allow on/off control. Controlled by the supply temperature, the geothermal heat pump was operated, irrespective of the room space load, which led to a waste of energy. Therefore, this study implemented the sequential operation of the geothermal heat pump by COP monitoring based on the optimal COP per geothermal heat pump. When the COP was 4.2 , the consumption of the least energy and the highest efficiency were achieved.

(2) The existing heat source was operational with a resulting waste of energy, even when the entire load was met by the geothermal system due to the system separation between the geothermal system and existing heat source system. Therefore, this study proposed an operation method to maximize the operation of the geothermal heat pump system by integrating the system, to enhance the efficiency, and minimize the use of an existing heat source.

(3) The system integration method preferentially uses a high-efficiency geothermal heat pump system because there is an integration of headers between the geothermal heat system and the absorption chiller-heater. The room load is removed using the absorption chiller-heater if the room load is not removed using the geothermal heat pump system alone. Compared to the existing operation method, the geothermal heat pump system increased its energy consumption by approximately $35 \%$, and the absorption chiller-heater consumption decreased by $45 \%$. Accordingly, the total energy consumption was reduced by approximately $40 \%$, which showed that the method contributed to an improvement in energy efficiency.

The present study proposed a system integration operation method with the existing heat source, the absorption chiller-heater, by applying the sequential operation by COP to improve the efficiency of the geothermal heat pump system. The proposed operation method met the room heat environment demands, and reduced the energy consumption, compared to the existing operation method. Follow-up studies will make it possible to efficiently operate the geothermal heat pump system by applying the proposed operation method to real buildings and evaluating the results. 
Acknowledgments: This research was supported by Basic Science Research Program through the National Research Foundation of Korea (NRF) funded by the Ministry of Education, Science and Technology. (NRF-2014R1A1A2058912).

Author Contributions: All authors contributed to this work. Young-Ju Jung performed the result analysis of simulation and wrote the major part of this article. Hyo-Jun Kim conducted the energy simulation. Bo-Eun Choi summarized simulation data. Jae-Hun Jo performed the result discussion and gave technical support. Young-Hum Cho was responsible for this article and gave conceptual advice.

Conflicts of Interest: The authors declare no conflict of interest.

\section{References}

1. Intergovernmental Panel on Climate Change (IPCC). The 5th Assessment Report of Intergovernmental Panel on Climate Change; IPCC: Geneva, Switzerland, 2013.

2. Korea Energy Economics Institute (KEEI). 2015 Energy Info.; KEEI: Ulsan, Korea, 2016.

3. Ministry of Trade, Industry and Energy. Act on the Promotion of the Development, Use and Diffusion of New and Renewable Energy; Ministry of Trade, Industry and Energy: Sejong, Korea, 2014.

4. Jang, H.; Seong, Y.; Cho, Y.; Kim, Y.; Jo, J. An Analysis of Problems and the Current Status of Renewable Energy System in Buildings. Korean Sol. Energy 2012, 32, 75-82. [CrossRef]

5. Haehnlein, S.; Bayer, P.; Blum, P. International legal status of the use of shallow geothermal energy. Renew. Sustain. Energy Rev. 2010, 14, 2611-2625. [CrossRef]

6. Luo, J.; Rohn, J.; Bayer, M.; Priess, A. Thermal efficiency comparison of borehole heat exchangers with different drillhole diameters. Energies 2013, 6, 4187-4206. [CrossRef]

7. Rees, S.; Curtis, R. National deployment of domestic geothermal heat pump technology: Observations on the UK experience 1995-2013. Energies 2014, 7, 5460-5499. [CrossRef]

8. Nam, Y.J. Study on the optimum design of a heat pump system using solar and ground heat. Korean J. Air-Cond. Refrig. Eng. 2012, 24, 509-514. [CrossRef]

9. Hwang, I.J.; Woo, N.S.; Lee, H.C. A study on the performance evaluation of hybrid energy system with geothermal and solar heat sources. Korean J. Air-Cond. Refrig. Eng. 2006, 18, 279-286.

10. Son, B.; Kwon, H. Performance prediction on the application of a ground-source heat pump system in an office building. Korean J. Air-Cond. Refrig. Eng. 2014, 26, 409-415. [CrossRef]

11. Jang, J. A Study on the Performance Prediction and Verification of Integrated Ground Source Heat Pump System. Master's Thesis, Chungnam National University, Daejeon, Korea, 2011.

12. Park, J.; Kim, J.; Hong, W.; Ahn, C. Research on the cooling performance evaluation of groundwater heat pump system for residence house. J. Archit. Inst. Korea 2008, 24, 273-280.

13. Jung, Y.; Kim, H.; Shin, K.; Jo, J.; Kim, Y.; Cho, Y. Development of the hybrid operation method of a multi-geothermal heat pump system and absorption chiller-heater. Energies 2015, 8, 9320-9343. [CrossRef]

14. Lee, S. The Research on the Energy-Saving Method of the Geothermal Heat-Pump Cooling and Heating System Introduced to the College Building. Master's Thesis, Kyungpook National University, Daegu, Korea, 2013.

15. Bakirci, K.; Ozyurt, O.; Comakli, K.; Comakli, O. Energy analysis of a solar-ground source heat pump system with vertical closed-loop for heating applications. Energy 2011, 36, 3224-3232. [CrossRef]

16. Yang, W. Experimental performance analysis of a direct-expansion ground source heat pump in Xiangtan, China. Energy 2013, 59, 334-339. [CrossRef]

17. Kim, W.; Choi, J.; Cho, H. Performance analysis of hybrid solar-geothermal $\mathrm{CO}_{2}$ heat pump system for residential heating. Renew. Energy 2013, 50, 596-604. [CrossRef]

18. Ozgener, O.; Hepbasli, A. Modeling and performance evaluation of ground source (geothermal) heat pump systems. Energy Build. 2007, 39, 66-75. [CrossRef]

19. Salvalai, G. Implementation and validation of simplified heat pump model in IDA-ICE energy simulation environment. Energy Build. 2012, 49, 132-141. [CrossRef]

20. Ally, M.R.; Munk, J.D.; Baxter, V.D.; Gehl, A.C. Exergy analysis and operational efficiency of a horizontal ground-source heat pump system operated in a low-energy test house under simulated occupancy conditions. Int. J. Refrig. 2012, 35, 1092-1103. [CrossRef]

21. Ally, M.R.; Munk, J.D.; Baxter, V.D.; Gehl, A.C. Exergy and energy analysis of a ground-source heat pump for domestic water heating under simulated occupancy conditions. Int. J. Refrig. 2013, 36, 1417-1430. [CrossRef] 
22. Chen, C.; Sun, F.; Feng, L.; Liu, M. Underground water-source loop heat-pump air-conditioning system applied in a residential building in Beijing. Appl. Energy 2005, 82, 331-344. [CrossRef]

23. Sivasakthivel, T.; Murugaesan, K.; Sahoo, P.K. A study on energy and $\mathrm{CO}_{2}$ saving potential of ground source heat pump system in India. Renew. Sustain. Energy Rev. 2014, 32, 278-293. [CrossRef]

24. Yu, S.W.; Jung, Y.J.; Kim, S.H.; Jo, J.H.; Kim, Y.S.; Cho, Y.H. A study on the optimized control strategies of geothermal heat pump system and absorption chiller-heater. Int. J. Energy Res. 2014, 38, 1083-1098. [CrossRef]

(c) 2016 by the authors; licensee MDPI, Basel, Switzerland. This article is an open access article distributed under the terms and conditions of the Creative Commons Attribution (CC-BY) license (http://creativecommons.org/licenses/by/4.0/). 